\title{
Outcomes of intracorporeal lithotripsy of upper tract stones is not affected by BMI and skin-to-stone distance (SSD) in obese and morbid patients
}

\author{
Alexandre Pompeo, Wilson R. Molina, Cesar Juliano, David Sehrt, Fernando J. Kim \\ Department of Urology, Denver Health Medical Center (AP, WRM, DS, FJK), Denver; Department of \\ Urology, University of Colorado (WRM, FJK), Denver, CO, USA and Department of Urology, ABC Medical \\ School (CJ), Santo Andre, Brazil
}

\section{ABSTRACT}

Purpose: The purpose of this study is to determine if body mass index (BMI) and stone skin distance (SSD) affect stone free rate (SFR) in obese and morbid obese patients who underwent flexible URS for proximal ureteral or renal stones $<20 \mathrm{~mm}$.

Materials and Methods: A retrospective chart review was performed of consecutive patients that underwent flexible URS. Inclusion criteria were: proximal ureteral stones and renal stones less than $20 \mathrm{~mm}$ in the preoperative computed tomography (CT). SFR were then compared according to SSD and BMI.

Results: A total of 153 patients were eligible for this analysis, 49 (32.02\%) with SSD < $10 \mathrm{~cm}$ and $104(67.97 \%)$ with SSD $\geq 10 \mathrm{~cm}$. The mean stone size was $10.5 \pm 6.4 \mathrm{~mm}$. The overall SFR in our study was 82.4\%. The SFR for the SSD $<10$ and $\geq 10$ were $79.6 \%$ and $83.7 \%$ respectively $(\mathrm{p}=0.698)$ and for BMI $<30, \geq 30$ and $<40$ and $\geq 40$ were $82.9 \%$, $81.7 \%$ and $90.9 \%$ respectively. Regression analysis showed no affect between BMI or SSD regarding SFR.

Conclusion: Ureteroscopy should be considered as a first-line of treatment for renal/proximal stones in obese and morbid obese patients. URS may be preferable to SWL in obese patients independently of the SSD, BMI or the location of proximal stones.

\section{ARTICLE INFO}

\author{
Key words: \\ Ureteroscopy; Obesity; Body \\ Mass Index; Calculi; Urinary \\ Bladder Calculi
}

Int Braz J Urol. 2013; 39: 702-11

Submitted for publication:

August 06, 2012

Accepted after revision:

June 14, 2013

\section{INTRODUCTION}

The ideal treatment for proximal ureteral and renal stones has become controversial, with the noninvasive nature of shock wave lithotripsy (SWL) and the expansion of endoscopic digital technology. The 2007 update of the EAU/AUA ureteral stone guidelines (1) showed that both ureteroscopy (URS) and SWL should be considered first-line therapy for proximal ureteral stones, as opposed to just SWL as previously reported. On the other hand SWL has emerged as the primary treatment of choice for renal calculi less than $1.5-2 \mathrm{~cm} \mathrm{(2).}$

In that context, the treatment of urolithiasis in obese patients has gained more importance in the last years since obesity rates have increased markedly since 1980 in the United States (3). Data from the National Center for Health Statistics (2009-2010) showed that $35.7 \%$ of adults and $17 \%$ of children and adolescents in the United States were obese (4). According to the World Health Organization guidelines, a body mass index (BMI) of 18.5 to $25 \mathrm{~kg} / \mathrm{m}^{2}$ is considered normal, overweight is a BMI of 25 to 
29.9 , obese is a BMI $\geq 30$, and morbidly obese is a BMI $\geq 40$ (5).

Despite of the fact that SWL represents a highly successful non-invasive treatment in urolithiasis, several studies have demonstrated diminished efficacy in obese patients since this technique is considerably affected by skin-to-stone distances (6-9).

In such cases URS may rise as a better option. One of the greatest benefits of URS may be how its success rates are unaffected by obesity. Therefore URS may play an important role in treating our increasingly obese population maybe offering higher stone-free rates with a low retreatment incidence. The objective of this study is to determine if BMI and SSD affect SFR in obese and morbid obese patients who underwent flexible URS for proximal ureter or renal stones smaller than $20 \mathrm{~mm}$.

\section{MATERIALS AND METHODS}

A retrospective review was performed of consecutive patients undergoing flexible URS from August 2006 to January 2012 at our institution after IRB approval. Patients with proximal ureteral stone and renal stones less than $20 \mathrm{~mm}$ in the preoperative Computed Tomography (CT) were included. Each stone was stratified by skin to stone distance (SSD), which is commonly measured for SWL but not typically for URS. SSD was calculated by measuring the average of three distances (Figure-1A) from the center of the stone to skin at 0,45 and 90 angles on non-contrast preoperative CT as previously described (7).

Based on SWL literature to predict SFR, we chose to compare success rates in two different groups: $\mathrm{SSD}<10 \mathrm{~cm}$ and $\mathrm{SSD}>10 \mathrm{~cm}$. We also chose to compare success rates of morbid obese with non-morbid obese patients.

After diagnosis of the stone disease, all patients were informed of the treatment option and the risks of the procedure and informed consent was obtained. URS and stone fragmentation were performed with the patient in the lithotomy position under general anesthesia (Figure-1B). A 7.5 Fr Olympus flexible ureteroscope with an access sheath was used in all procedures. The sto- ne was accessed and lithotripsy was performed, if needed, using Holmium laser. Larger fragments were removed using a basket. Following complete stone removal, endoscopic inspection was performed through the entire collecting system to evaluate for any residual stones. Also fluoroscopy with or without magnificence was utilized to evaluate residual fragments. Stone free was defined as an absence of stone fragments or fragments $\leq 2$ $\mathrm{mm}$ during the following URS after a rigorous endoscopic and fluoroscopic inspection. A stent was placed at the end of the procedure in all cases. Patients with questionable stone free status after URS were submitted to CT scan in the follow-up. Patient's characteristics (age, gender, and Body Mass Index), stone size, location, operative time, and stone free rate were evaluated. Patients were considered obese if BMI $\geq 30$ and $<40 \mathrm{~kg} / \mathrm{m}^{2}$ and morbid obese if BMI $\geq 40 \mathrm{~kg} / \mathrm{m}^{2}$ according to the World Health Organization guidelines.

Statistical analyses were performed using the $\mathrm{R}$ version 2.11 software (the $\mathrm{R}$ foundation for Statistical Computing, Vienna, Austria). A p-value $<0.050$ was considered significant. Chi-square, Student t-tests, and ANOVA were used for comparing SSD $<10$ to SSD $\geq 10$ $\mathrm{cm}$ and non-obese with obese and morbid obese results. Univariate logistic regression models were constructed to test the significance of BMI and SSD in ureteroscopy. Data are presented as mean \pm standard deviation and frequency (percentage of total).

\section{RESULTS}

A total of 309 patients underwent flexible URS from August 2006 to January 2012, of which 153 met the inclusion criteria and were included in the analysis. The overall mean age was $45.1 \pm 14.5$ years, the mean BMI was $29.8 \pm 7.8$ $\mathrm{kg} / \mathrm{m}^{2}$, the mean SSD was $11.6 \pm 3.0 \mathrm{~cm}$ and the mean stone size was $10.5 \pm 6.4 \mathrm{~mm}$. Interestingly, ureteral stones had a higher SSD than renal stones $(13.0 \pm 2.6 \mathrm{~cm}$ and $10.4 \pm 2.8 \mathrm{~cm}$, respectively) and was statistically significant $(\mathrm{p}<0.001)$. The overall SFR in our study was $82.4 \%$. Overall pre-stenting occurred in $37.3 \%$ of our patients. No major complication necessitating prolonged 
hospital stay or new surgical procedure was observed in our analysis.

Table- 1 shows the patients demographics and clinical data stratified by SSD. The mean SSD for the group with $<10 \mathrm{~cm}$ was $8.4 \mathrm{~cm}$ versus 13.1 $\mathrm{cm}$ in the other group. The SFR for $<10 \mathrm{~cm}$ and $\geq 10 \mathrm{~cm}$ were $79.6 \%$ and $83.7 \%$ respectively (p
$=0.698)$. Table-2 demonstrates the demographics and clinical data stratified by BMI. Table-3 showed location and SFR stratified by SSD and BMI. No statistical difference was observed in SFR rates between the groups. The pre-stenting rates between the groups were $28.1 \%$ and $47.9 \%$ for BMI < $30 \mathrm{~kg} / \mathrm{m}^{2}$ and BMI $\geq 30 \mathrm{~kg} / \mathrm{m}^{2}$ respectively. The

Figure 1 - Demonstrating non correlation between SFR and BMI or SSD.
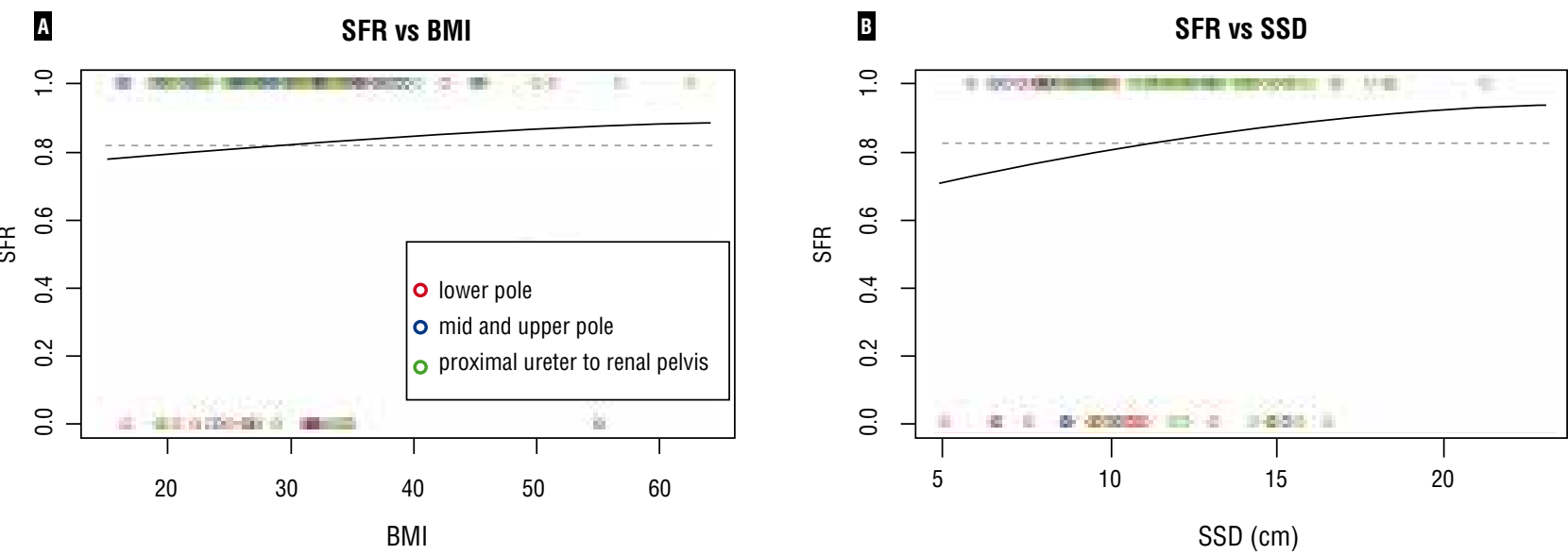

$A=$ Measurement of SSD.

B $=$ Position of patient to perform URS

Table 1 - Demographics stratified by SSD.

\begin{tabular}{|c|c|c|c|}
\hline Skin Stone Distance & $\mathrm{SSD}<10 \mathrm{~cm}$ & $\mathrm{SSD} \geq 10 \mathrm{~cm}$ & $p$-value \\
\hline N & $49(32.0 \%)$ & $104(68.0 \%)$ & \\
\hline Age (year) & $40.5 \pm 14.2$ & $47.3 \pm 14.2$ & 0.004 \\
\hline BMI (kg/m2) & $24.6 \pm 5.6$ & $32.2 \pm 7.7$ & $<0.001$ \\
\hline \multicolumn{4}{|l|}{ Sex } \\
\hline Female & $23(46.9 \%)$ & $61(58.7 \%)$ & 0.236 \\
\hline Male & $26(53.1 \%)$ & $43(41.3 \%)$ & \\
\hline Stone Size (mm) & $9.6 \pm 4.6$ & $11.0 \pm 7.0$ & 0.152 \\
\hline Number of Stones & $1.8 \pm 1.5$ & $2.0 \pm 1.4$ & 0.345 \\
\hline Pre-stenting & $11(22.4 \%)$ & $46(44.2 \%)$ & 0.036 \\
\hline ORT (min.) & $72.0 \pm 38.2$ & $73.9 \pm 39.2$ & 0.787 \\
\hline
\end{tabular}

ORT = Operating room time; SFR: stone free rates 
Table 2 - Demographics stratified by BMI.

\begin{tabular}{|c|c|c|c|c|}
\hline Body Mass Index & $<30$ & $\geq 30$ and $<40$ & $\geq 40$ & $p$-value \\
\hline N & $82(53.6 \%)$ & $60(39.2 \%)$ & $11(7.2 \%)$ & \\
\hline Age (yr) & $43.8 \pm 15.7$ & $47.1 \pm 15.8$ & $44.5 \pm 15.1$ & 0.379 \\
\hline BMI $\left(\mathrm{kg} / \mathrm{m}^{2}\right)$ & $24.2 \pm 3.4$ & $33.9 \pm 2.1$ & $49.0 \pm 6.7$ & $<0.001$ \\
\hline \multicolumn{5}{|l|}{ Sex } \\
\hline Female & $36(43.9 \%)$ & $39(65.0 \%)$ & $9(81.8 \%)$ & 0.008 \\
\hline Male & $46(56.1 \%)$ & $21(35.0 \%)$ & $2(18.2 \%)$ & \\
\hline Stone Size (mm) & $9.9 \pm 5.0$ & $10.1 \pm 7.6$ & $13.9 \pm 6.5$ & 0.024 \\
\hline Number of Stones & $1.8 \pm 1.3$ & $2.1 \pm 1.2$ & $2.4 \pm 1.5$ & 0.159 \\
\hline Pre-stenting & $23(28.0 \%)$ & $30(50.0 \%)$ & $4(36.4 \%)$ & 0.028 \\
\hline ORT (min.) & $77.5 \pm 42.8$ & $66.2 \pm 35.1$ & $85.2 \pm 23.4$ & 0.582 \\
\hline
\end{tabular}

ORT = Operating room time; SFR: stone free rates

pre-stenting rates were higher in the obese and morbid obese groups and it may contribute to the higher SFR observed in the morbid obese patients. The reason for pre-stenting these patients were pain $57.9 \%$ and infection $28.1 \%$, other causes such as dilation and acute renal failure complete the reasons for pre stenting. Pre-stenting was performed in 36 (63.2\%) ureteral cases and 21 (36.8\%) renal cases. There was no difference in stone free rates between gender in either obese or non-obese groups ( $p=0.133$ and 0.824 , respectively).

Regression analysis showed no affect between BMI or SSD with stone free rates (Figure-1). We also observed no statistical difference in the treatment of morbid obese patients. Although improvements were seen as BMI and SSD increased, regression coefficients for these variables were not significant ( $p=0.546,0.178$ respectively). The higher stone free rate in obese patients may have been a result of treating more non-lower pole stones and pre-stenting.

Stratified for location (Table-3), the initial stone free rates for proximal ureteral, non-lower pole renal, and lower pole stones ranged from 66.7 $\%$ to $89.7 \%$ for all SSD categories and from 66.7 to $100 \%$ for BMI groups. Sub analysis between location subgroups further revealed no statistical significance between SSD $(p=0.606,0.918$, and 0.928 respectively) or BMI groups ( $\mathrm{p}=0.794$, $0.515,0.875$ respectively). Neither SSD nor BMI appeared to influence the efficacy of flexible URS treatment, since no significant difference was observed in the stone free rates between patients.

\section{DISCUSSION}

Urinary stone treatment improvements over the recent years allowed endoscopic procedures to be performed in almost any situation. The incidence of urolithiasis varies in the literature affecting $5-15 \%$ of the population worldwide (10) with a prevalence of $8.8 \%$ in the United States in recent years (11). The parallel growth in prevalence of obesity and morbid obesity over the past decades has increased the management of stone disease in this population $(12,13)$. The association between urolithiasis and obesity is established in the literature and has shown that weight gain increases the urinary excretion of substances such as oxalate and uric acid, leading to stone formation (14-16). 
Table 3 - Stone Location and Stone Free Rates stratified by SSD and BMI.

\begin{tabular}{|c|c|c|c|c|}
\hline By Skin-to-Stone Distance & & & & \\
\hline Location & $<10 \mathrm{~cm}$ & $\geq 10 \mathrm{~cm}$ & p-value & \\
\hline Proximal ureter and UPJ & $9(18.4 \%)$ & $58(55.8 \%)$ & $<0.001$ & \\
\hline Renal pelvis, Upper and Mid pole & $22(44.9 \%)$ & $17(16.3 \%)$ & 0.027 & \\
\hline Lower pole & $18(36.7 \%)$ & $29(27.9 \%)$ & 0.358 & \\
\hline Total & $49(32.0 \%)$ & $104(68.0 \%)$ & & \\
\hline \multicolumn{5}{|l|}{ Stone Free Rate } \\
\hline Overall & $39 / 49(79.6 \%)$ & $87 / 104(83.7 \%)$ & 0.698 & \\
\hline Proximal ureter and UPJ & $8 / 9(88.9 \%)$ & $52 / 58(89.7 \%)$ & 0.606 & \\
\hline Renal pelvis, Upper and Mid pole & $19 / 22(86.4 \%)$ & $14 / 17(82.4 \%)$ & 0.918 & \\
\hline Lower pole & $12 / 18(66.7 \%)$ & $21 / 29(72.4 \%)$ & 0.928 & \\
\hline \multicolumn{5}{|l|}{ By Body Mass Index } \\
\hline Location & $<30$ & $\geq \mathbf{3 0}$ and $<40$ & $\geq \mathbf{4 0}$ & p-value \\
\hline Proximal ureter and UPJ & $40(48.8 \%)$ & $23(38.3 \%)$ & $4(36.4 \%)$ & 0.406 \\
\hline Renal pelvis, Upper and Mid pole & $21(25.6 \%)$ & $14(23.4 \%)$ & $4(36.4 \%)$ & 0.660 \\
\hline Lower pole & $21(25.6 \%)$ & $23(38.3 \%)$ & $3(27.3 \%)$ & 0.259 \\
\hline Total & $82(53.6 \%)$ & $60(39.2 \%)$ & $11(7.2 \%)$ & \\
\hline \multicolumn{5}{|l|}{ Stone Free Rate } \\
\hline Overall & $68(82.9 \%)$ & $48(80.0 \%)$ & $10(90.9 \%)$ & 0.67 \\
\hline Proximal ureter and UPJ & $35 / 40(87.5 \%)$ & $21 / 23(91.3 \%)$ & $4 / 4(100.0 \%)$ & 0.794 \\
\hline Renal pelvis, Upper and Mid pole & $19 / 21(90.5 \%)$ & $11 / 14(78.6 \%)$ & $3 / 4(75.0 \%)$ & 0.515 \\
\hline Lower pole & $14 / 21(66.7 \%)$ & $16 / 23(69.5 \%)$ & $3 / 3(100.0 \%)$ & 0.875 \\
\hline
\end{tabular}

Studies also indicate that obese patients suffer from urolithiasis twice as much as the non-obese and recurrence rates are close to 50\% (17). Conversely, due to conflicting data and the development of new endoscopic instruments the optimal management of stone disease in these patients is still in discussion.

Although SWL has become a very common treatment modality for urolithiasis in the past decade, stone clearance depends on a number of factors such as stone characteristics (burden, location and density), renal related (anatomical features) and pertinently patient related (BMI, muscle-skeletal defor- mity and SSD). Pareek et al. (7) demonstrated that BMI independently predicted the SWL outcome. They suggested that patients with a BMI $\geq 30 \mathrm{~kg} /$ $\mathrm{m}^{2}$ would be more suitable treated by endoscopic manipulation. In another study by the same author, SSD of $12 \mathrm{~cm}$ was an independent predictor of unfavorable outcomes, suggesting that SSD might more accurately link obesity with SWL failure (18). Further, SWL may also produce detrimental side effects such as hypertension and diabetes mellitus, which are already risk factors associated with obesity (19). 
Another option for treatment of upper urinary stones in obese patients may be percutaneous nephrolithotomy (PNL), which has been shown to have good outcomes regardless of BMI. In a study of 114 patients stratified by ideal body weight, overweight, obese and morbidly obese, there was no difference between groups and the stone-free rates were 90\% (20). Although the literature showed that PNL in obese and morbidly obese patients yields a stone-free rate that is comparable to that achieved in non obese patients, PNL presents greater perceived technical difficulties especially in obese and morbid obese patients such as positioning, puncture of the collecting system and longer operative time. In this setting, ureteroscopy resurge as an important option for these patients.

The application of ureteroscopy as a minimally invasive treatment for stones has advanced remarkably with the improvements in technology in such a way that nowadays it is an attractive option for intervention in upper tract stones. In addition, ureteroscopy does offer a non-invasive approach and is considered safer and easier to perform. Furthermore, ureteroscopy does not appear to be affected by body habitus. In a retrospective, single institution study, the stone free rates were similar between 107 obese patients and non-obese patients (21). Another recent study published by Best et al. (22) showed statistically equivalent SFR in obese (91\%) and non-obese (81\%) patients who underwent flexible URS for proximal ureteral stones. Thus, the improved success rates of URS to SWL may promote this approach as the method of choice to treat our increasingly obese population. More recently, Delorme et al. analyzed the feasibility of flexible URS in obese patients with equivalency in terms of operative time, rate of complications and overall SFR compared to non-obese patients (23). A contemporary meta-analysis published by Aboumazzouk OM regarding the feasibility of URS in obese patients showed good outcomes with a SFR of 87.5\% (24).

Our results corroborates with the literature with SFR (82.4\%) consistent with previous studies. Moreover, our analysis conveyed that BMI had no influence on SFR. We found that SFR are similar for non-obese, obese, and morbid obese patients. Similar to BMI, SSD had no effect on overall SFR.
Interestingly, we found that there was a difference in the SSD between renal and ureteral stones by 3 $\mathrm{cm}$. To the best of our knowledge, this is the first time that this difference has been described in the literature. This is probably due to the anatomical medial position of the UPJ and proximal ureter compared to the renal calices. This may explain why SWL may decrease its efficacy for ureteral stones. However, SSD between sub-groups $<10$ and $\geq 10 \mathrm{~cm}$ ) did not influence the success of URS. As such, SSD should not be included in the preoperative URS workup.

Pre-stenting is an important factor that can contribute for SFR and should be analyzed carefully. The higher incidence of co-morbidities in the obese and morbid obese groups could explain the higher frequency of pre-stenting and this fact may contribute to the higher SFR observed in our study especially in the morbid obese group.

The limitations of this study comprise a retrospective single institution analysis with relatively small number of patients. Furthermore, a standardized definition and methodology of assessing stone free status is lacking currently and not standardized in the literature. Although the clinical significance of residual stone size is presently unknown with stone free definitions ranging from the complete absent of stones to residual fragments $<4 \mathrm{~mm}$, our definition of stone free corroborates with a study that has shown that stones $>2 \mathrm{~mm}$ are related to a recurrent stone event (25). In addition, a relative number of radiological methods for evaluating post treatment stone free status was assessed in the literature such as CT, KUB (fluoroscopy), and Ultrasound, without clear characterization which one is the best method. We believe that our method minimized radiation and probably costs to the patients and health system.

From the best of our knowledge, there is no data about morbid obesity or SSD with the outcomes of flexible URS. Although based on a retrospective single institutional analysis, our study has a sufficient sample size to demonstrate that SSD and BMI are not relevant in terms of outcomes (SFR) for URS in these patient populations. Moreover, a clinical trial may be necessary to determine the optimal treatment of proximal/renal stones in obese patients. 


\section{CONCLUSIONS}

Ureteroscopy should be considered a first-line treatment for renal/proximal stones in obese and morbid obese patients. URS may be preferable to SWL in obese and morbid obese patients as it is independent of the SSD, BMI or the location of proximal stones. SSD does not have to be measured when considering ureteroscopy.

\section{ABBREVIATIONS}

URS $=$ Ureteroscopy

SSD $=$ Skin-to-stone distance

$\mathrm{BMI}=$ Body mass index

$\mathrm{SFR}=$ Stone free rate

\section{CONFLICT OF INTEREST}

None declared.

\section{REFERENCES}

1. Preminger GM, Tiselius HG, Assimos DG, Alken P, Buck C, Gallucci M, et al.: 2007 guideline for the management of ureteral calculi. J Urol. 2007; 178: 2418-34.

2. Jamshaid A, Ather MH, Hussain G, Khawaja KB: Single center, single operator comparative study of the effectiveness of electrohydraulic and electromagnetic lithotripters in the management of 10 - to $20-\mathrm{mm}$ single upper urinary tract calculi. Urology. 2008; 72: 991-5.

3. Ogden CL, Yanovski SZ, Carroll MD, Flegal KM: The epidemiology of obesity. Gastroenterology. 2007; 132: 2087-102.

4. Ogden CL, Carroll MD, Kit BK, Flegal KM: Prevalence of obesity in the United States, 2009-2010. NCHS Data Brief. 2012; 82: 1-8.

5. Stevens J, Cai J, Pamuk ER, Williamson DF, Thun MJ, Wood $\mathrm{JL}$ : The effect of age on the association between body-mass index and mortality. N Engl J Med. 1998; 338: 1-7.

6. El-Nahas AR, El-Assmy AM, Mansour 0, Sheir KZ: A prospective multivariate analysis of factors predicting stone disintegration by extracorporeal shock wave lithotripsy: thevalue of high-resolution noncontrast computed tomography. Eur Urol. 2007; 51: 1688-93; discussion 1693-4.

7. Pareek G, Armenakas NA, Panagopoulos G, Bruno JJ, Fracchia Já: Extracorporeal shock wave lithotripsy success based on body mass index and Hounsfield units. Urology. 2005; 65: 33-6.
8. Ng CF, Siu DY, Wong A, Goggins W, Chan ES, Wong KT: Development of a scoring system from noncontrast computerized tomography measurements to improve the selection ofupper ureteral stone for extracorporeal shock wave lithotripsy. J Urol. 2009; 181: 1151-7.

9. Patel T, Kozakowski K, Hruby G, Gupta M: Skin to stone distance is an independent predictor of stone-free status following shockwave lithotripsy. J Endourol. 2009; 23: 1383-5.

10. Moe OW: Kidney stones: pathophysiology and medical management. Lancet. 2006; 367: 333-44.

11. Scales CD Jr, Smith AC, Hanley JM, Saigal CS; Urologic Diseases in America Project: Prevalence of kidney stones in the United States. Eur Urol. 2012; 62: 160-5.

12. Stamatelou KK, Francis ME, Jones CA, Nyberg LM, Curhan GC: Time trends in reported prevalence of kidney stones in the United States: 1976-1994. Kidney Int. 2003; 63: 1817-23.

13. Ogden CL, Carroll MD, Curtin LR, McDowell MA, Tabak CJ, Flegal KM: Prevalence of overweight and obesity in the United States, 1999-2004. JAMA. 2006; 295: 1549-55.

14. Powell CR, Stoller ML, Schwartz BF, Kane C, Gentle DL, Bruce JE, et al.: Impact of body weight on urinary electrolytes in urinary stone formers. Urology. 2000; 55: 825-30. Erratum in: Urology. 2000; 56: 352.

15. Siener R, Glatz S, Nicolay C, Hesse A: The role of overweight and obesity in calcium oxalate stone formation. Obes Res. 2004; 12: 106-13.

16. Negri AL, Spivacow FR, Del Valle EE, Forrester M, Rosende G, Pinduli I: Role of overweight and obesity on the urinary excretion of promoters and inhibitors of stone formation in stone formers. Urol Res. 2008; 36: 303-7.

17. Sutherland JW, Parks JH, Coe FL: Recurrence after a single renal stone in a community practice. Miner Electrolyte Metab. 1985; 11: 267-9.

18. Pareek G, Hedican SP, Lee FT Jr, Nakada SY: Shock wave lithotripsy success determined by skin-to-stone distance on computed tomography. Urology. 2005; 66: 941-4.

19. Krambeck AE, Gettman MT, Rohlinger AL, Lohse CM, Patterson DE, Segura JW: Diabetes mellitus and hypertension associated with shock wave lithotripsy of renal and proximal ureteral stones at 19 yearsof followup. J Urol. 2006; 175: 1742-7.

20. Alyami FA, Skinner TA, Norman RW: Impact of BMI on clinical outcomes associated with PNL. Can Urol Assoc J. 2012; 15: 1-5.

21. Natalin R, Xavier K, Okeke Z, Gupta M: Impact of obesity on ureteroscopic laser lithotripsy of urinary tract calculi.Int Braz J Urol. 2009; 35: 36-41; discussion 41-2.

22. Best SL, Nakada SY: Flexible ureteroscopy is effective for proximal ureteral stones in both obese and nonobese patients: a two-year, single-surgeon experience. Urology. 2011; 77: $36-9$. 
23. Delorme G, Huu YN, Lillaz J, Bernardini S, Chabannes E, Guichard G, et al.: Ureterorenoscopy with holmium-yttriumaluminum-garnet fragmentation is a safe and efficient technique for stone treatmentin patients with a body mass index superior to $30 \mathrm{~kg} / \mathrm{m} 2$. J Endourol. 2012; 26: 239-43.

24. Aboumarzouk OM, Somani B, Monga M: Safety and efficacy of ureteroscopic lithotripsy for stone disease in obese patients: a systematic review of the literature. BJU Int. 2012; 110: E374-80.
25. Raman JD, Bagrodia A, Gupta A, Bensalah K, Cadeddu JA Lotan $Y$, et al.: Natural history of residual fragments following percutaneous nephrostolithotomy. J Urol. 2009; 181: 1163-8.

Correspondence address: Dr. Wilson Molina Chief of Endourology, Urological Department, Denver Health Hospital 777 Bannock St Denver, C0, 80204, USA Telephone: 1303 436-6575 E-mail: wilson.molina@dhha.org 


\section{EDITORIAL COMMENT}

Because of continuous technological advances in the field of endourology, several improved therapeutic options are now under investigation. Mainly regarding treatment of upper urinary tract lithiasis.

Currently, open stone surgery are virtually obsolete. Traditionally, ESWL and PCNL were considered the first-line therapies for renal stones. Nowadays, particularly retrograde intra-renal surgery (RIRS), using the new generation of flexible smaller-diameter ureteroscopes combined with a greater angle of deflection of the tip and advances in laser technology, has become an attractive option. According to current guidelines, ESWL and flexible ureteroscopy (f-URS) should be the first-line therapies for proximal ureteral stones. However, updated guidelines still list morbid obesity as an indication for open surgery. In investigative and clinical scenarios, considerable interest exists if RIRS could achieve better outcomes than ESWL, PCNL in a growing population of obese and super obese patients (1).

Obesity has reached an epidemic stage worldwide. Obesity has been demonstrated as an independent risk factor for urinary stones. Generally, obese patients have a diet rich in lithogenic substances, high prevalence of chronic kidney disease (CKD), insulin resistence and diabetes (low urine $\mathrm{pH}$ ), even weight control therapies (medication and bariatric surgery) favors urolithiasis. Futhermore, obesity and morbid obesity has been associated with large spectrum of potential postoperative complications and unsuccessfully ESWL and PCNL. Public policy on obesity is mandatory. Educational programs should inform these patients about obesity and association with anesthetic and surgery complications and encouraged them to make lifestyle modifications to improve their quality of life and limit health risks such as urolithiasis.

Because fat is distributed irregularly in waist circumference and dorso in patients with the same BMI, several groups has proposed the
SSD as a independent predictive factor of SFR. Beyond the SSD, positioning and technique may worsen outcomes after ESWL and PCNL. Although patient size and diameter does not affect the procedure itself neither limit surgery exposure during f-URS, the retrograde management of renal stones is regurlarly challenging, mostly in lower pole located stones.

In this study, the authors reported their experience in management proximal ureteral and renal stones $<20 \mathrm{~mm}$ using flexible ureteroscopy and laser lithotriptor. They retrospectively studied skin to stone distance (SSD) and body mass index (BMI) as possible prognostic factors. They concluded that neither SSD nor BMI are predictive factors for stone-free rate (SFR) follow URS/RIRS.

Similar retrospectively efforts have been published demonstrating that obese patients can be treated safely and successfully with RIRS (2). Therefore, SSD should not be measure when a f-URS or a RIRS is planned.

Also, the authors discussed the lack of standardization of the definition of SFR after upper tract surgery in literature. The image exam follow procedure was not protocol-driven and only patients with questionable stone-free status were submitted to CT scan. Ultrasound and KUB radiography's sensitivity and specificity for identifying residual urinary stones are even lower in obese patients and, probably, not the best tests to reassure the stone-free status in this population. CT image should be standardized in investigate scenario. Other potential bias is the limited mumber of each sub-obesity group, i.e. obese, morbidly obese, or super obese.

In summary, although its acknowledged limitations of this retrospective study and limited number of patients, the authors should be commended for their efforts and originality, since the paper provides additional clinical data suggesting that SSD and BMI do not influence the SFR after f-URS or RIRS. As the role of RIRS 
continues to expand, multi-institutional, prospective and randomized trials comparing ESWL, PCNL and RIRS outcomes are needed to confirm

\section{REFERENCES}

1. Resorlu B, Unsal A, Ziypak T, Diri A, Atis G, Guven S, et al.: Comparison of retrograde intrarenal surgery, shockwave lithotripsy, and percutaneous nephrolithotomy for treatment of medium-sized radiolucent renal stones. World J Urol. 2012; 22. In Press if f-URS and RIRS should be or not the gold-standard for proximal/renal stones in obese patients. Health economic outcome should be analyzed.
2. Caskurlu T, Atis G, Arikan O, Pelit ES, Kilic M, Gurbuz C: The impact of body mass index on the outcomes of retrograde intrarenal stone surgery. Urology. 2013; 81: 517-21.

\section{Dr. Flavio L. Heldwein}

Discipline of Urology Universidade do Sul de Santa Catarina (UNISUL) Av. José Acácio Moreira, 787 - Dehon, Tubarao, SC, 88704-900, Brazil Telephone: + 5548 3621-3000 E-mail: flavio.lobo@gmail.com 